\title{
Small Cell Osteosarcoma of Mandible: A rare case report and review of literature
}

\author{
Amit Sethi* 1, Shweta Rehani ${ }^{2}$, Kundendu Arya ${ }^{3}$ \\ ${ }^{1}$ MDS, MFDSRCPS(Glasgow),Senior Resident, Unit of Oral and Maxillofacial Surgery, Oral Health Sciences Centre, Postgra- \\ duate Institute of Medical Education and Research, Chandigarh, INDIA \\ ${ }^{2}$ MDS, Assistant Professor, Dept. of Oral Pathology, Manipal College of Dental College Sciences, Manipal, Karnataka, INDIA \\ ${ }^{3}$ MDS Senior Resident, Oral Pathology, Institute of Dental Sciences,Banaras Hindu University, Varanasi,Uttar Pardesh, INDIA \\ *communicating author
}

Correspondence:

Kundendu Arya Bhishen MDS

Senior Resident

Dept of Oral Pathology

Institute of Dental Sciences

Banaras Hindu University

Varanasi, Uttar Pardesh, INDIA

E-mail-amitsethi_maxfax@yahoo.com

Received: 31/01/2009

Accepted: 14/04/2010
Sethi A, Rehani S, Arya K. Small Cell Osteosarcoma of Mandible: A rare case report and review of literature. J Clin Exp Dent. 2010;2(2):e96-9.

http://www.medicinaoral.com/odo/volumenes/v2i2/jcedv2i2p96.pdf

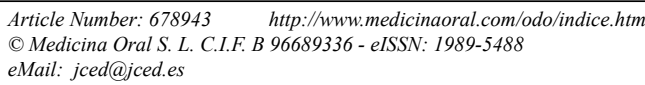

\begin{abstract}
Osteosarcoma is the most common primary malignant tumor of bone but only $5 \%$ of these tumours occur in the jaws. Of all the varieties of osteosarcoma, the juxtacortical type is rare and comprises only less than $4 \%$ of all osteosarcomas. Juxtacortical osteosarcoma is further subdivided into parosteal (low grade) and periosteal (high grade). Osteosarcomas can be categorized histologically mainly into chondroblastic, osteoblastic, fibroblastic and numerous others. One of the rare histological variant is small cell osteosarcoma which consists of sheets of round cells that produce an osteoid matrix. The aim of this article is to present a rare case of periosteal osteosarcoma of mandible which on histopathological examination showed characteristics of small cell tumour.
\end{abstract}

Key words: Osteosarcoma, small cell variant, periosteal type. 


\section{Introduction}

The term osteosarcoma refers to a group of primary malignant neoplasms affecting bone. The World Health Organization recognizes several variants which differ in location, clinical behavior and degree of cellular atypia (1). The majority are intramedullary (conventional) but a small number may be juxtacortical or rarely extraskeletal. Juxtacortical osteosarcomas can be further subdivided into two clinicoapthological variants: periosteal and paraosteal. One of the rare histological variant is small cell osteosarcoma which consists of sheets of round cells that produce an osteoid matrix (2). This paper presents a rare case of periosteal mandibular osteosarcoma which histologically was found to be a small cell tumour.

\section{Case Report}

An 18 year old male presented to our department with painless, diffuse swelling near left angle of mandible. No history of trauma, pain/mobility of teeth, parasthesia/anaesthesia or trismus was reported. Medical history was non contributary. Extraoral examination revealed a bony hard, non-tender, non-mobile swelling with normal overlying skin. There was no cervical lymphadenopathy. Intraoral examination revealed a roundish, hard mass close to lower left molar region. Associated teeth were firm and asymptomatic. Panaromic radiograph showed a mixed radiolucent-radio-opaque lesion in relation to left mandibular molars and submentovertex radiograph was significant for bucco-lingual expansion of lower border of mandible at left angle region (Fig. 1). Lateral oblique

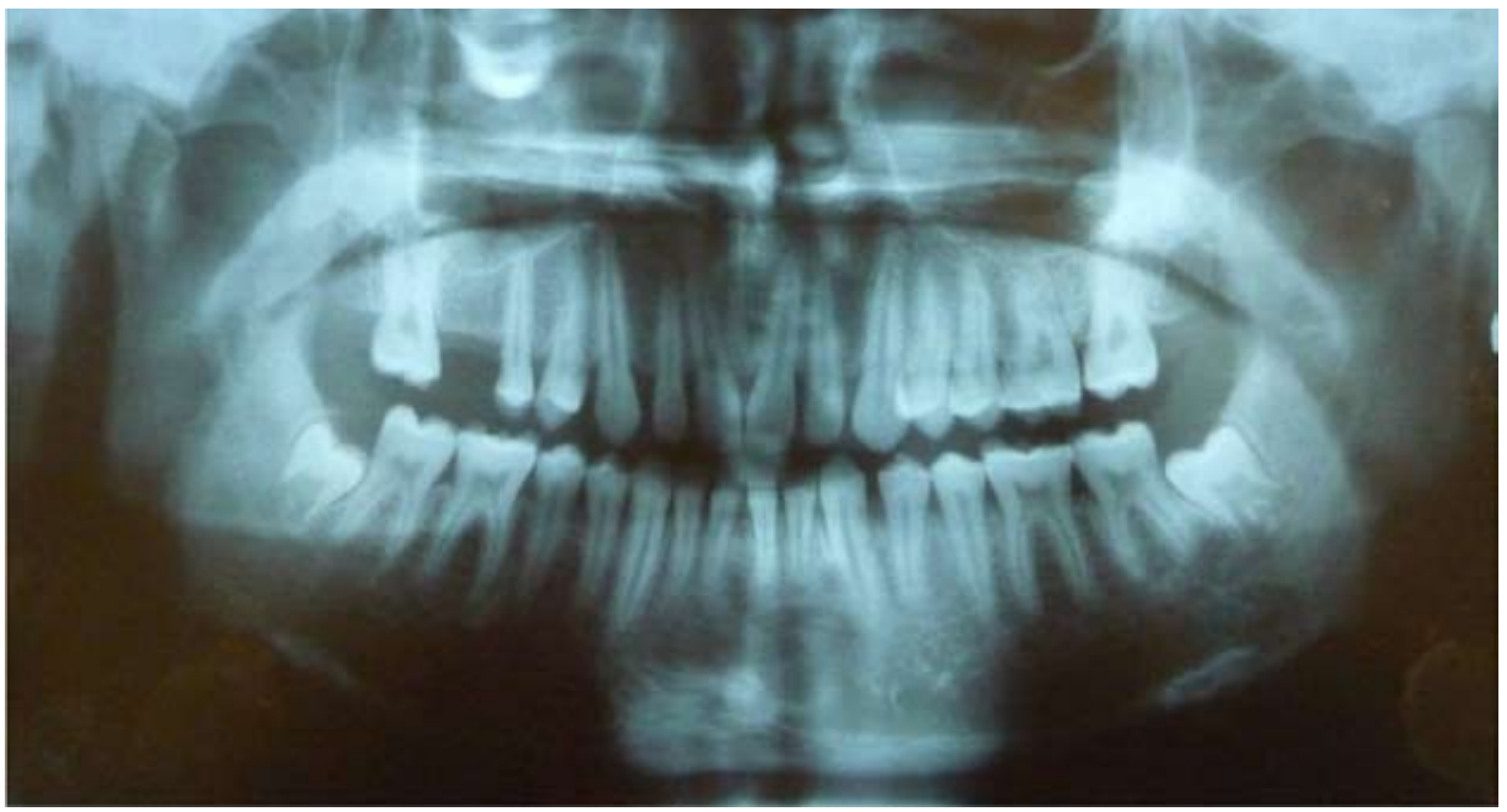

Fig. 1. Panoramic radiograph revealing an ill defined radiolucency corresponding to left second and third molars

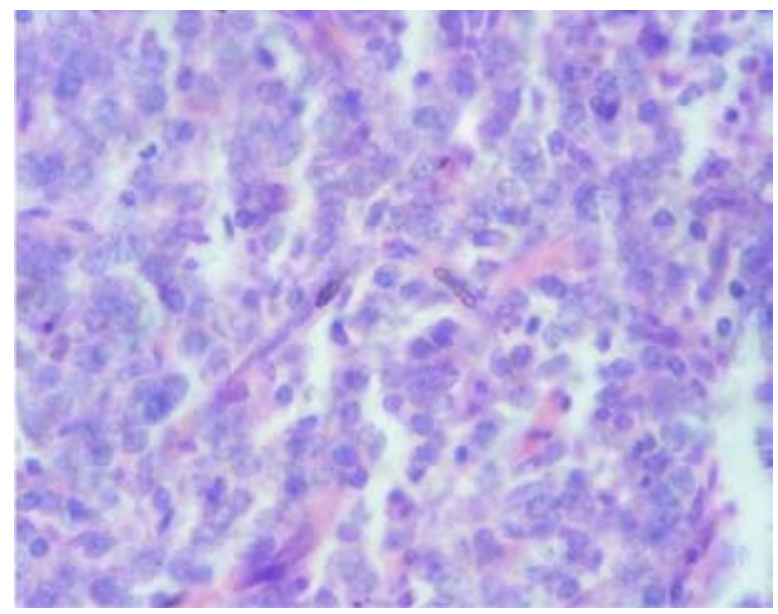

Fig. 2. Microphotograph showing sheets of round cells with indistinct cellular outline and distinct nuclear boundaries. $H \&$ E stain $100 x$

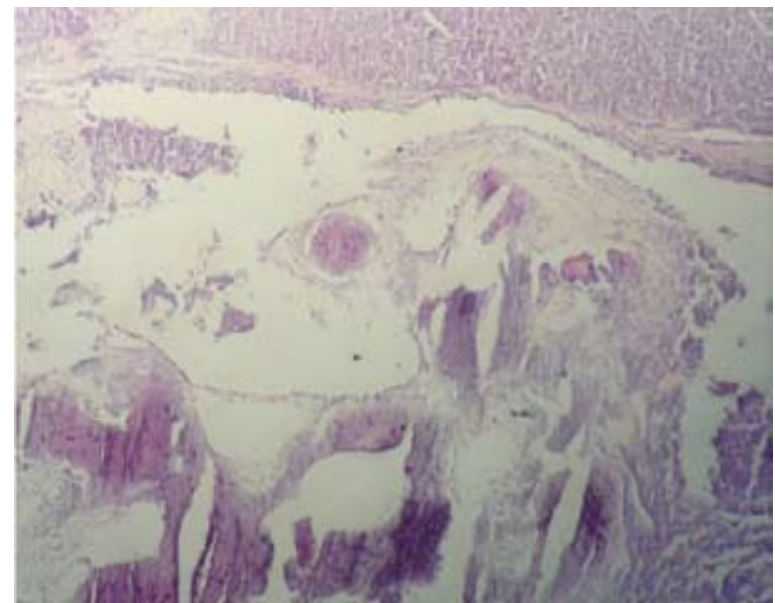

Fig. 3. Microphotograph showing mass of tumour osteoid in cellular stroma $H \&$ E stain. $10 x$ 
view revealed a radiolucent area with irregular border in left body region in relation to left mandibular molar. Computed tomography scan was not done. Hematological and biochemical laboratory tests were normal. Patient was taken up for surgery under general anaesthesia. Lesion was exposed intraorally and wide excision with $1 \mathrm{~cm}$ margins all around was done. On gross examination, the excised biopsy sample measured $3 \times 2 \times 2 \mathrm{~cm}$, was firm, irregular and grayish-white in colour. Histopathological examination revealed round to ovoid tumor cells arranged in the form of sheets or lobules in a scanty stroma. The individual tumor cells had indistinct cellular but distinct nuclear outline with nuclei being either hyperchromatic or vesiculated (Fig.2). Stroma exhibited numerous blood vessels packed with red blood cells and foci of tumor osteoid (Fig.3).

\section{Discussion}

Osteosarcomas have been classified according to their site of origin into conventional type i.e. arising within the medullary cavity, juxtacortical tumor arising from periosteal surface and extraskeletal osteosarcomas, arising rarely in soft tissues. Juxtacortical osteosarcoma is a rare neoplasm, comprising only less than $4 \%$ of all osteosarcomas and occurs less commonly than the conventional tumour (3).

Zarbo et al. (4) suggested that juxtacortical osteosarcoma can be further subdivided into two cliniopat-hologic variants: parosteal (low grade) and periosteal (high grade). Till date only 17 cases of juxtacortical have been reported and out of which 8 cases were periosteal.

Periosteal osteosarcoma, a distinct entity, is an extremely rare tumor. According to Unni et al. (5) series, male predominance was seen which was in contrast to the female predominance in parosteal type. It has peak occurrence in the second decade which is similar to that seen in conventional osteosarcoma but parosteal osteosarcoma tends to occur in slightly older age group.

Radiographically, periosteal osteosarcoma presents as a small radiolucent lesion always located on peripheral cortex and does not show a sunray pattern (5). The roengentographic features of the present case fulfill the criteria entitled for periosteal variant having an ill-defined radiolucency on intact bone surface with no marrow involvement. The radiographic differential diagnosis included peripheral osteoma, juxtacortical osteosarcoma and myositis ossificans. The osteoma presents as more intense and uniformly dense tumor because of relatively larger osseous component and the absence of cartilaginous matrix. The striae of osteoma are fewer and closer to each other while myositis ossificans shows growth in single direction with the greatest density in the peripheral parts (6).

The microscopic appearance of the periosteal osteosarcoma is characterized by seemingly intact cortex, masses of abnormal- appearing cartilage and osteoid extending into the soft tissues, peripheral chondroid areas arranged perpendicular to the cortex, central malignant appearing osteoid and little tendency to infiltrate adjacent soft tissues (4). However, in contrast, the present case was composed of round tumor cells present in the either sheets or lobules in scanty stroma. Tumor cells were either round/ ovoid shape, having distinct cell and nuclear outline with nucleus being either hyperchromatic/vesiculated. Few PAS+ clear cells were also observed. At places, fibrillar lace-like osteoid matrix in between the tumor cells and foci of tumor osteoid were seen in the stroma. The tumor osteoid helps in differentiating this lesion from other small cell tumors.

Primary small round cell tumors of the bones are a heterogenous group of malignant neoplasms which comprise of Ewing's sarcoma, peripheral neuroectodermal tumor, lymphoma, mesenchymal chondrosarcoma and small cell osteosarcoma. Microscopically they resemble each other but each has characteristic biologic and genetic features that make them a separate entity. The diagnosis of small cell tumors can be made correctly by analyzing clinical and pathological reports thoroughly and by applying a panel of immunohistochemical markers (7). Small cell osteosarcoma, a variant of osteosarcoma, was first reported by Sim et al. in 1979 (8). The anatomic distribution of small cell osteosarcoma is similar to that of conventional osteosarcoma. Radiographically, it can either resemble Ewing's sarcoma or conventional osteosarcoma. Ayala et al. (9) have documented three histological patterns- Ewing's sarcoma-like, lymphoma-like and small spindle cell like. Sim et al. (8) described the small cell osteosarcoma under low power as tumor composed of small round cells separated by dense fibrous tissue. On higher magnification, the tumor cells can be round or ovoid, uniform, similar to Ewing's sarcoma or may show variation in size. Nuclei are generally small to medium $(6.7-15 \mu \mathrm{m})$, round to oval in shape. Nucleoli can be inconspicuous to prominent. The nuclear chromatin can be dispersed finely or clumped. The cytoplasmic borders are distinct. Mitotic figures are abundant. Hemangiopericytic pattern, myxoid, cord-like arrangement or epitheloid features can also be seen (9). Though glycogen is often found in Ewing's sarcoma, it is not specific for Ewing's sarcoma and can even occur in rhabdomyosarcomas, neuroblastomas and few cases of small cell osteosarcoma. Sim et al. (8) did not find glycogen in their study but Martin et al. (10) and Ayala et al. (9) have reported glycogen in cells. Even in our case, few clear cells were PAS + . Therefore, glycogen presence does not rule out small cell osteosarcoma.

The presence of osteoid is a pre-requisite for differentiating small cell osteosarcoma from Ewing's sarcoma. Although even in Ewing's sarcoma reactive bone sclerosis and soft tissue mineralization can be seen in the 
form of periosteal laminated bone but in small cell osteosarcoma mineralized tumor matrix is usually noted. However, the diagnosis of small cell osteosarcoma depends on the identification of produced osteoid which again can be quite variable. The problem can be in the absence of mineralization or to differentiate hyalinized collagen from osteoid or even sampling error could influence the diagnosis. The defining feature present in small cell osteosarcoma is mineralized matrix and in the absence of identifiable mineralized matrix, it is difficult to differentiate fibrin deposit found between individual cells of Ewing's sarcoma from osteoid. Nakajima et al. (11) stated that if in doubt the diagnosis of Ewing's sarcoma should be made. The other small cell tumors including Ewing's sarcoma should be ruled out using immunohistochemistry. CD-99 positivity has been noted in small cell osteosarcoma (12). Positive reaction for either of these: LCA, S-100, EMA, SMA, factor VIII, smooth muscle actin, neuron specific enolase, synaptophsyin, etc would favor the exclusion of small cell osteosarcoma (13). Most small cell osteosarcoma show vimentin positivity and occasional minority may be muscle specific actin (HHF-35) positive. Our case showed CD99 positivity and LCA negativity.

The next logical question is that how important is to distinguish small cell osteosarcoma from Ewing's sarcoma. The prognosis of small cell osteosarcoma was considered to be worse than conventional osteosarcoma and Ewing's sarcoma (14). It is a known fact that perisoteal osteosarcoma is capable of local recurrence and distant metastasis while the parosteal type is considered to be a low-grade neoplasm (5). However, very little information is available regarding small cell osteosarcoma.

The overall survival rate depends upon prognostic factors including tumor size, location and histologic grade. Higher survival rate and lesser metastasis incidence have been reported in the osteosarcomas of jaws when compared to those occurring in extremities. Although histologically small cell osteosarcoma prognosis is considered to be poorer than conventional osteosarcoma or Ewing's sarcoma juxtacortical variant being relatively slow in growth has a much more favourable prognosis. Literature review has shown that patients treated initially by aggressive local or even radical procedures such as hemimandibulectomy fared better. This is important on two counts. Firstly, wide excision of adjacent bone and periosteum not only prevents recurrence by removing small satellite lesions but also prevents the local spread of tumour along bone surface. Secondly, recurrent lesions are much more aggressive having a higher grade of malignancy which increases risk of further recurrence or metastasis. Chemotherapy plays a role in modern management of osteosarcoma by improving primary control and eradicating systemic disease. It plays a part in treatment of conventional osteosarcoma of jaws and juxtacortical tumours of long bones despite their lower risk of metastasis. However its role in managing juxtacortical tumour of jaws is less clear. Wide resection of local or radical nature depending on the site of lesion would seem to be the initial treatment of choice reserving chemotherapy for recurrent cases in combination with surgery $(15,16)$.

Although osteosarcomas of the jaws are less common and less aggressive, it is important to evaluate the clinical, roentgenographic and histopathologic features to recognize the exact variant. Accurate diagnosis is the key to establish an effective therapeutic regimen that will improve the survival rate of the patient. We present case of periosteal osteosarcoma of small cell type to emphasize the importance of differentiating the small cell osteosarcoma from other variants considering its poorer prognosis when compared to conventional osteosarcoma.

\section{References}

1. Schajowicz F, Sissons HA, Sobin LH. The World Health Organization's histologic classification of bone tumors. A commentary on the second edition. Cancer. 1995;75:1208-14.

2. Edeiken J, Raymond AK, Ayala AG, Benjamin RS, Murray JA, Carrasco HC. Small-cell osteosarcoma. Skeletal Radiol. 1987;16:621-8.

3. Yoon JH, Yook JI, Kim HJ, Ho Cha I, Kim J. Periosteal osteosarcoma of the mandible. J Oral Maxillofac Surg. 2005;63:699-703.

4. Zarbo RJ, Regezi JA, Baker SR. Periosteal osteogenic sarcoma of the mandible. Oral Surg Oral Med Oral Pathol. 1984;57:643-7.

5. Unni KK, Dahlin DC, Beabout JW. Periosteal osteogenic sarcoma. Cancer. 1976;37:2476-85.

6. Stevens GM, Pugh DG, Dahlin DC. Roentgenographic recognition and differentiation of parosteal osteogenic sarcoma. Am J Roentgenol Radium Ther Nucl Med. 1957;78:1-12.

7. Hameed M. Small round cell tumors of bone. Arch Pathol Lab Med. 2007;131:192-204.

8. Sim FH, Unni KK, Beabout JW, Dahlin DC. Osteosarcoma with small cells simulating Ewing's tumor. J Bone Joint Surg Am. 1979;61:207-15

9. Ayala AG, Ro JY, Raymond AK, Jaffe N, Chawla S, Carrasco H, et al. Small cell osteosarcoma. A clinicopathologic study of 27 cases. Cancer. 1989;64:2162-73.

10. Martin SE, Dwyer A, Kissane JM, Costa J. Small-cell osteosarcoma. Cancer. 1982;50:990-6.

11. Nakajima H, Sim FH, Bond JR, Unni KK. Small cell osteosarcoma of bone. Review of 72 cases. Cancer. 1997;79:2095-106.

12. Devoe K, Weidner N. Immunohistochemistry of small round-cell tumors. Semin Diagn Pathol. 2000;17:216-24.

13. Devaney K, Vinh TN, Sweet DE. Small cell osteosarcoma of bone: an immunohistochemical study with differential diagnostic considerations. Hum Pathol. 1993;24:1211-25.

14. Glasser DB, Lane JM, Huvos AG, Marcove RC, Rosen G. Survival, prognosis, and therapeutic response in osteogenic sarcoma. The Memorial Hospital experience. Cancer. 1992;69:698-708.

15. Hartman KR, Triche TJ, Kinsella TJ, Miser JS. Prognostic value of histopathology in Ewing's sarcoma. Long-term follow-up of distal extremity primary tumors. Cancer. 1991;67:163-71.

16. Millar BG, Browne RM, Flood TR. Juxtacortical osteosarcoma of the jaws. Br J Oral Maxillofac Surg. 1990;28:73-9. 